\title{
DOMINANCE OF TARDIGRADA IN ASSOCIATED FAUNA OF TERRESTRIAL MACROALGAE Prasiola crispa (CHLOROPHYTA: PRASIOLACEAE) FROM A PENGUIN ROOKERY NEAR ARCTOWSKI STATION (KING GEORGE ISLAND, SOUTH SHETLAND ISLANDS, MARITIME ANTARCTICA)
}

http://dx.doi.org/10.4322/apa.2014.083

\begin{abstract}
Adriana Galindo Dalto ${ }^{1, *}$, Geyze Magalhães de Faria ${ }^{1}$, Tais Maria de Souza Campos ${ }^{1}$, Yocie Yoneshigue Valentin ${ }^{1}$
\end{abstract}

${ }^{1}$ Laboratório de Macroalgas Marinhas, Instituto de Biologia, Universidade Federal do Rio de Janeiro - UFRJ, Av. Carlos Chagas Filho, 373, sala A1-94, Centro de Ciências da Saúde, Ilha do Fundão, CEP 21941-902, Rio de Janeiro, RJ, Brazil

$$
\text { *e-mail: agdalto@gmail.com }
$$

\begin{abstract}
Tardigrada are among the microinvertebrates commonly associated to terrestrial vegetation, especially in extreme environments such as Antarctica. In the austral summer 2010/2011, Tardigrada were found in high densities on Prasiola crispa sampled at penguin rookeries from Arctowski Station area (King George Island). Taxonomic identifications performed to date suggest that the genus Ramazzottius is the dominant taxa on P. crispa. This genus has been reported for West Antarctica and Sub-Antarctic Region. In this context, the present work intends to contribute to the knowledge of the terrestrial invertebrate fauna associated to P. crispa of the ice-free areas around Admiralty Bay.
\end{abstract}

Keywords: microinvertebrates, terrestrial macroalgae, tardigrada, Ramazzottius

\section{Introduction}

Tardigrada are micrometazoans (average 250-500 $\mu \mathrm{m}$ ) that present a large distribution in variety of diverse habitats, from rain forests to arid polar environments, including nunataks and mountain tops to abyssal plains of the oceanic regions (Brusca \& Brusca, 2007; McInnes, 2010a). In terrestrial environments, Tardigrada are abundant, especially in mosses and lichens, which is the main component of the crypticfauna. Many linmo-terrestres tardigrades can survive to total desiccation in a state of cryptobiosis (ametabolic state) that is a protection against desiccation and freezing under natural conditions, but anydrobiosis also allows a resistance against unnatural abiotic extremes (Jönsson \& Bertolani, 2001). Actually, about 800 species of Tardigrada have been described from marine, freshwater and terrestrial environments (Nelson \& Marley, 2000).
Antarctic Tardigrada were at the beginning described by Murray (1906) and Richters (1908) (apud Convey \& McInnes, 2005), after species lists of Antarctic Tardigrada were prepared by Morikawa (1962), Sudzuki (1964), Jennings $(1976,1979)$ and Utsugi \& Ohyama $(1989,1993)$. Tardigrada species are currently known from the continental and Maritime Antarctica biogeographical zones (Pugh, 1993; Convey \& McInnes, 2005). Actually, 17 genera and 48 species have been described for associated fauna of terrestrial vegetation of ice-free areas in Antarctica and SubAntarctica regions (McInnes, 2010b), 11 of these species were reported for King George Island (South Shetland Islands, Maritime Antarctica) by Utsugi \& Ohyama (1993).

In King George Island, terrestrial vegetation is almost exclusively cryptogamic, comprising mostly mosses, 
liverworts, lichens, algaes (Smykla et al., 2007). In this island, mats of the nithphilous algae Prasiola crispa occupy wet areas extremely high nutrient concentration at active rookeries at the coastal regions around Admiralty Bay (South Shetland Islands, Maritime Antarctica) (Smykla et al., 2007). According to Jennings $(1976,1979)$ this foliaceae algae is among the substrates with higher faunal species richness and Tardigrada is among these organisms (Broady, 1989).

Nevertheless, Antarctic terrestrial biota is known to have low diversity, a high degree of endemism and clear patterns of biogeographic distribution defined by consistent biological and climatic differences (Convey \& McInnes, 2005; Convey \& Stevens, 2007). Added to this, the Antarctic terrestrial biota include organisms ecophysiology adapted to environmental pressures involving very low temperatures, nutrient limitation, environmental radiation, lack of liquid water, desiccation and physical abrasion (Convey et al., 2008). Recent studies have shown that this biota has an ancient origin and has persisted in isolation for ten million years (Convey \& Stevens, 2007; Convey et al., 2009; Chow \& Convey, 2007). These characteristics result in the terrestrial communities of Antarctica being particularly sensitive to the effects of human presence in the region and to climate change. In this context, the present study intends to contribute to the knowledge of the composition of the Tardigrada assemblages on the terrestrial macroalgae Prasiola crispa of the ice-free areas around Admiralty Bay.

\section{Materials and Methods}

Prasiola crispa were sampled on the rocks and soil adjacent to the penguin rookeries of Ornithologist Stream area (Polar Polish Arctowski Station, King George Island) in January 2011 (XXIX Brazilian Antarctic Operation) (Figure 1).

Three samples of $3 \mathrm{~cm}^{2}$ were observed in vivo and later preserved in formaldehyde $4 \%$ for posterior analysis, quantification and identification of the fauna. In the

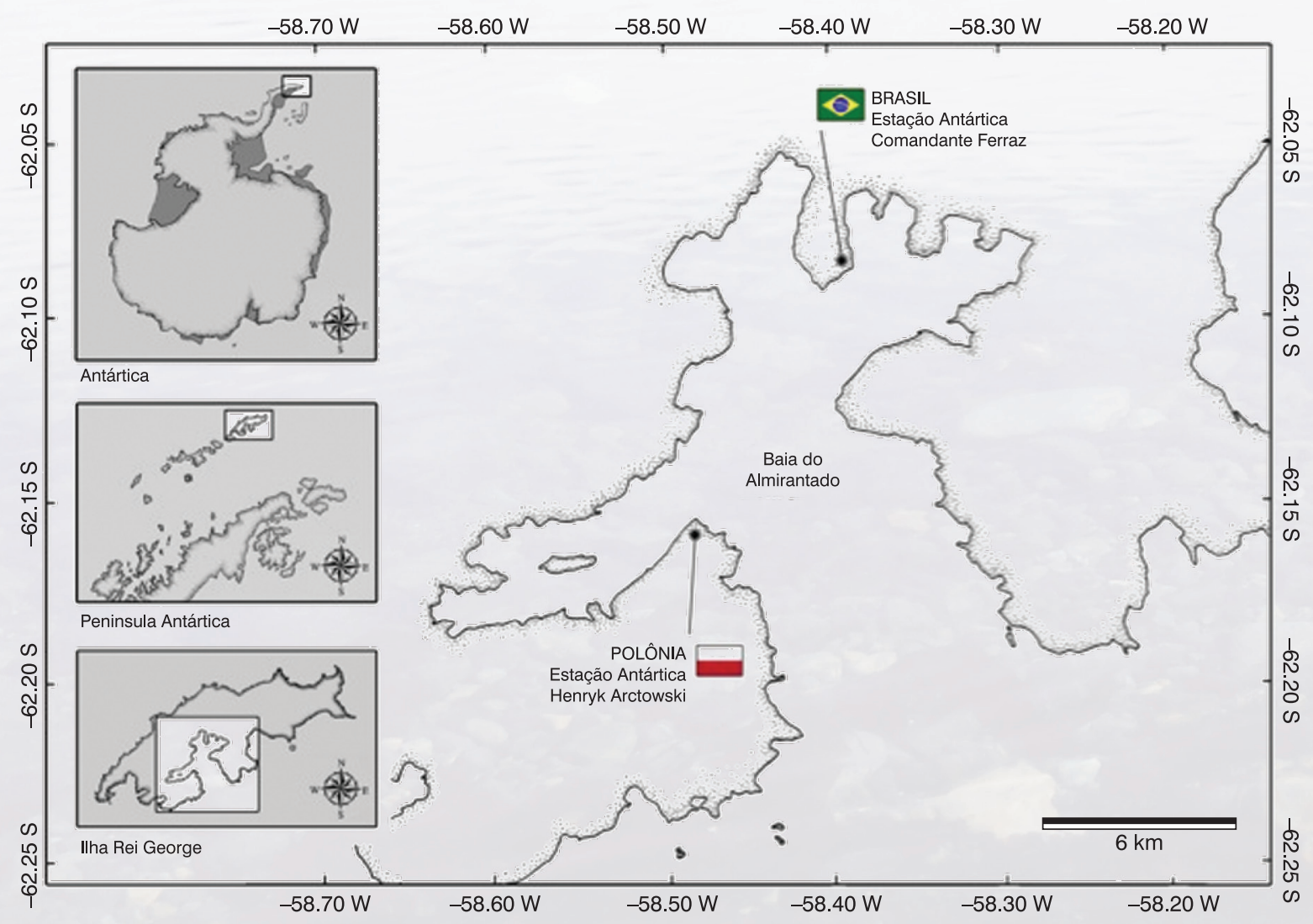

Figure 1. Location of Admiralty Bay (King George Island, South Shetland Islands, Antarctic Peninsula), highlighted the scientific stations of Brazil and Poland. Illustration: Rafael Bendayan de Moura. 
laboratory the organisms were separated through sieves (500 and $38 \mu \mathrm{m}$ size meshes). After the total organism quantifications under stereoscopic microscope, Tardigrada specimens were removed and post fixed in GAW solution (Glycerin - Acetic acid - Water), before being passed through a glycerol series and mounted in Faure's medium (McInnes et al., 2001). After drying, slides were ringed with glycerol. Taxonomic identifications were performed by optical microscopy and based on Pilato \& Binda (2010) keys.

\section{Results}

The associated microfauna of Prasiola crispa were composed by Rotifera, Nematoda, Tardigrada, Acari and Collembola. Tardigrada was the taxa found in greatest density, up to 7002,67 ind. $\mathrm{cm}^{-2}\left(x=2842,11\right.$ ind. $\mathrm{cm}^{-2}, \mathrm{n}=3$ ) (Table 1), representing $66 \%$ of the total microfauna. The taxonomic identifications conducted so far indicate that the specimens found Tardigrada specimens belong to the Family Hypsibiidae, genus Ramazzotius Binda \& Pilato, 1986. Other identifications still in progress, and at the end identified specimens will be deposited in the collection.

\section{Discussion and Conclusion}

Jennings (1976) when studied the Tardigrada from the Antarctic Peninsula and Scotia Ridge Region found a high dominance of tardigrada only on sites of the foliose alga Prasiola crispa. According Convey \& McInnes (2005) some terrestrial ecosystems dominated by Tardigrades, and organisms which would generally be ubiquitous such as Nematode can also very often be absent. This showed the
Tardigrada preference for the relatively rich organic soils rather than moss and peat substrates.

At the moment, taxonomic identifications showed that Tardigrada specimens founded on the Prasiola crispa samples from Ornithologist Stream are the family Hypsibiidae and genus Ramazzotius Binda \& Pilato, 1986. The Hypsibiidae family are a significant and dominant in polar habitats (McInnes \& Pugh, 2007). This dominance cannot be explained only by the fact that it possesses features such as cold tolerance (Cryptobiosis), aerial dispersion or partenogenisis, whereas other families (e.g. Macrobiotidae, Echiscidae) also have such features. McInnes (2007) suggest that this dominance was more likely to food sources, many Hypsibiidae are hydrophilic, bactereophages and/ or algivores, a factor that can be an advantage to colonize polar habitats.

Ramazzottius are cosmopolitan genus (Ramazzotti \& Maucci, 1983). Ramazzottius are widespread throughout the world (Ramazzotti \& Maucci, 1983; McInnes, 1994), including the previous record of Antarctica continental and sea. Among the many collection of bryophytes, species of Echiniscus, Hypsibius, Macrobiotus (and segregate genera), Milsenium and Ramazzottius seem particularly common. The genus Ramazzottius is characterized by Hypsibius-type claws, but only Ramazzottius has a long and straight basal portion on the outer claw more strongly developed than the secondary branch in addition to a thin main branch inserted high on the basal portion by means of a flexible tract (C) (Bertolani \& Rebecchi 1993). Sometimes this tract is very lightly sclerified and the primary branch seems almost completely separate from the rest of the claw (Nelson

Table 1. Composition and density (ind. $\mathrm{cm}^{-2}$ ) of microfauna associated to Prasiola crispa.

\begin{tabular}{|c|c|c|c|c|c|c|c|}
\hline Taxa & Arctowski 22 & Arctowski 23 & Arctowski 24 & Sum & Ind. $\mathrm{cm}^{-2}$ & DP & $\begin{array}{c}\text { Relative } \\
\text { abundance (\%) }\end{array}$ \\
\hline Tardigrada & 147,67 & 1376,00 & 7002,67 & 8526,33 & 2842,11 & 2984,39 & 66,0 \\
\hline Nematoda & 88,67 & 112,67 & 3965,33 & 4166,67 & 1388,89 & 1821,85 & 32,3 \\
\hline Acari & 1,67 & 45,00 & 67,33 & 114,00 & 38,00 & 27,26 & 0,9 \\
\hline Rotifera & 74,00 & 0,00 & 0,00 & 74,00 & 24,67 & 34,88 & 0,6 \\
\hline Collembola & 1,00 & 2,67 & 28,67 & 32,33 & 10,78 & 12,67 & 0,3 \\
\hline Total Microfauna & 314,00 & 1536,33 & 11064,00 & 12914,33 & 4304,78 & 4805,47 & 100,0 \\
\hline
\end{tabular}



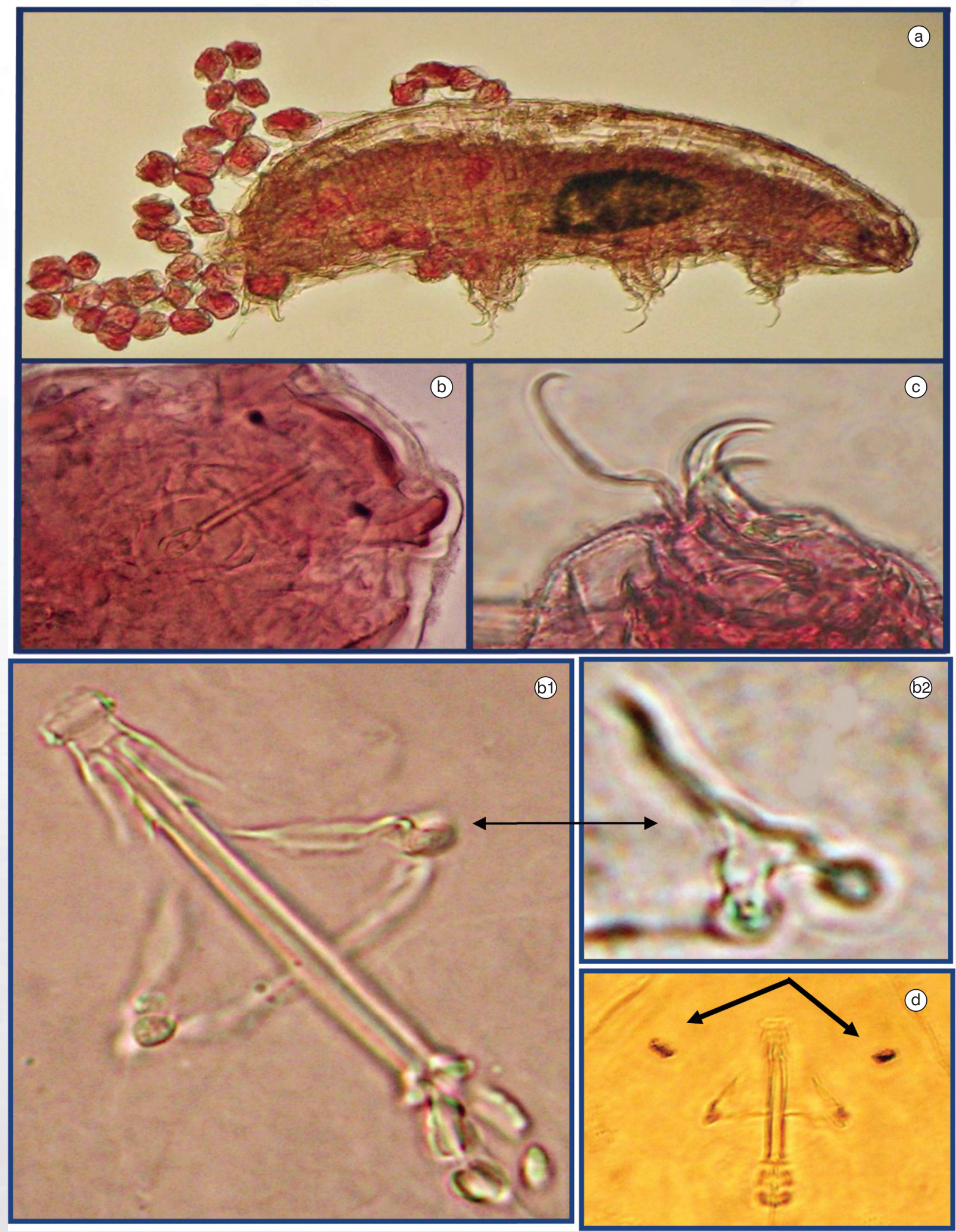

Figure 2. Taxonomic details of genus Ramazzottius. a) animal in dorso-lateral; b) bucco-pharyngeal apparatus (b1: buccal armature Hypsibius type - pharyngeal apophyses and macroplacoids and b2: stylet furcae shape (typically-shaped); c) Ramazzotius-type claw d)s Sensory organs. 
\& Marley, 2000), a blunted apophysis, asymmetric on the frontal plane, for stylet muscle insertion onto the buccal tube (B); two paired anteriorly located elliptical sensory organs and dorsolaterally (D) (Bertolani \& Rebecchi 1993) (Figure 2).

Specific taxonomic identification is in process, furthermore, recent research studies have shown that Prasiola crispa possesses potential bioactive substances for insecticide activity, which is indicative of how important it is to increase the knowledge about this alga and all the associated microfauna related to it.

\section{Acknowledgements}

This work integrates the National Institute of Science and Technology Antarctic Environmental Research (INCT-
APA) that receives scientific and financial support from the National Council for Research and Development (CNPq process: $n^{\circ}$ 574018/2008-5) and Carlos Chagas Research Support Foundation of the State of Rio de Janeiro (FAPERJ $n^{\circ}$ E-16/170.023/2008). The authors also acknowledge the support of the Brazilian Ministries of Science, Technology and Innovation (MCTI), of Environment (MMA) and InterMinistry Commission for Sea Resources (CIRM). Adriana G. Dalto, Geyze M. Faria and Tais M. S. Campos thank those responsible for the Postdoctoral Research Fellow (CAPES/ FAPERJ E-26/102.016/2009), Technical Support fellow (DTI-3 CNPq/INCT-APA 383830/2011-7) and Scientific Initiation fellow (CNPq/INCT-APA 110657/2011-0), respectively.

\section{References}

Bertolani, R. \& Rebecchi, L. (1993). A revision of the Macrobiotus hufelandi group (Tardigrada, Macrobiotidae) with some observationson the taxonomic characters of eutardigrades. Zoological Scripta, 22: 127-152.

Binda, M.G. \& Pilato, G. (1986). Ramazzottius, nuovo genere di eutardigrado (Hypsibiidae). Animalia (Catania). 13: $159-166$.

Broady, P.A. (1989). Survey of algae and other terrestrial biota at Edward VII Peninsula. Marie Byrd Land. Antarctic Science, 1, 215224.

Brusca, R.C. \& Brusca, G.J. (2007). Invertebrados. 2. ed. Rio de Janeiro: Guanabara Koogan. 936 p.

Chow, S.L. \& Convey, P. (2007). Spatial and Temporal variability across life's hierarchies in the terrestrial Antarctic. Philosophical Transactions of The Royal Society B: Biologiacal Science, 362: 2307-2331.

Convey, P. \& Mclnnes, S. (2005). Exceptional Tardigrade - Dominated Ecosystems in Ellsworth Land, Antarctica. Ecology, 86(2): 519-527.

Convey, P. \& Stevens, M.I. (2007). Antarctic biodiversity. Science, 317: 1877-1878.

Convey, P.; Gibson, J. A. E.; Hillenbrand, C. D.; Hodgson, D. A.; Pugh, P. J. A.; Smellie, J. L.; Stevens, M. I. (2008). Antarctic terrestrial life-challenging the history of the frozen continent? Biological Reviews, 83: 103-117.

Convey, P.; Bindschadler, R.; Prisco, G.; Fahrbach, E.; Gutt, J.; Hodgson, D.A.; Mayewski, P.A.; Summerhayes, C.P. \& Turner, J. (2009). Antarctic climate change and the environment. Antarctic Science, 21: 541.

Jennings, P.G. (1976). Tardigrada from the Antarctic Peninsula and Scotia Rigde Region. British Antarctic Survey Bulletin, 47: 77-95

Jennings, P.G. (1979). The Signy Island terrestrial reference sites: X. Population dynamics of Tardigrada and Rotifera. British Antarctic Survey Bulletin, 42: 89-105.

Jönsson, K. \& Bertolani, R. (2001). Facts and fiction about long-term survival in tardigrades. Journal of Zoology, 255: 121123. http://dx.doi.org/10.1017/S0952836901001169

McInnes, S. (1994). Zoogeographic distribution of terrestrial/freshwater tardigrades from current literature. Journal of Natural History, 28: 257-352.

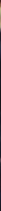


Mclnnes, S.J.; Chown, S.L.; Dartnall, H.J.G. \& Pugh, P.J.A. (2001). Milnesium tardigradum a monitor of high altitude micro-invertebrates on sub-Antarctic Marion Island. Proceedings of the Eighth International Symposium on Tardigrada, Copenhagen. Zoologischer Anzeiger, 240(3-4): 461-466.

McInnes, S. J. \&. Pugh, P.J.A. (2007). An attempt to revisit the global biogeography of limno-terrestrial Tardigrada. Proceedings of the Tenth International Symposium on Tardigrada. Journal of Limnology, 66(Suppl. 1): 90-96.

Mclnnes, S. (2010a). Taxonomy, biodiversity and biogeography: Tardigarda and Antarctic meiofauna. Ph.D. Anglia Ruskin University. 77p. Available from: <http://hdl.handle.net/10540/216030>.

McInnes, S.J. (2010b) Echiniscus corrugicaudatus (Heterotardigrada; Echiniscidae) a new species from Ellsworth Land, Antarctica. Polar Biology, 33: 59-70.

Morikawa, K. (1962). Notes on some tardigrada fr om the Antarctic region. Biol. Results Jpn. Antarct Res. Exp. (JARE), 17: 3-7.

Nelson, D.R. \& Marley, N.J. (2000). The biology and ecology of lotic Tardigrada. Freshwater Biology, 44: 93-108.

Pilato, G. \& Binda, M.G. (2010). Definition of families, subfamilies, genera and subgenera of the Eutardigrada, and keys to their identification. Zootaxa, 2404: 1-54.

Pugh, P.J.A. (1993). A synonymic catalogue of the Acari from Antarctica, the sub-Antarctic islands and the Southern Ocean. Journal of Natural History, 27: 323-421.

Ramazzotti, G.; Maucci, W. (1983). II Phylum Tardigrada. 3rd ed. Memorie dell. Istituto Italiano di Idrobiologia. v. 41, p. 1-1012.

Smykla, J.; Wolek, J. \& Bercikowski, A. (2007). Zonation of vegetation related to penguin rookeries on King George Island, Maritime Antarctic. Arctic Antarctic and Alpine Research, 39: 143-151.

Sudzuki, M. (1964). On the microfauna of the Antarctic region. I. Moss-water community at Langhovde, J.A.R.E. 1956-1962 Scientific Reports Series E, 19: 1-30.

Utsugi, K. \& Ohyama, Y. (1989). Antarctic tardigrada. Proceedings of the NIPR Symposium on Polar Biology, 2: 190-197.

Utsugi, K. \& Ohyama, Y. (1993). Antartic Tardigrada III. Fildes Peninsula of King George Island. Proceedings of the NIPR Symposium on Polar Biology, 6: 139-151. 